\title{
Risk Factors for Colonization of $E$. coli in Atlantic Bottlenose Dolphins (Tursiops truncatus) in the Indian River Lagoon, Florida
}

\author{
Adam M. Schaefer, ${ }^{1}$ Gregory D. Bossart, ${ }^{1,2}$ Marilyn Mazzoil, ${ }^{1}$ \\ Patricia A. Fair, ${ }^{3}$ and John S. Reif ${ }^{1,4}$ \\ ${ }^{1}$ Marine Mammal Research and Conservation Program, Harbor Branch Oceanographic Institute, Florida Atlantic University, \\ Ft. Pierce, FL 34946, USA \\ ${ }^{2}$ Georgia Aquarium, Atlanta, GA 30313, USA \\ ${ }^{3}$ Center for Coastal Environmental Health and Biomolecular Research, NOS, NOAA, Charleston, SC 29142, USA \\ ${ }^{4}$ Department of Environmental and Radiological Health Sciences, College of Veterinary Medicine and Biomedical Sciences, \\ Colorado State University, Fort Collins, CO 80532, USA
}

Correspondence should be addressed to Adam M. Schaefer, aschaefer@hboi.fau.edu

Received 9 June 2011; Revised 2 August 2011; Accepted 3 August 2011

Academic Editor: Pam R. Factor-Litvak

Copyright (C) 2011 Adam M. Schaefer et al. This is an open access article distributed under the Creative Commons Attribution License, which permits unrestricted use, distribution, and reproduction in any medium, provided the original work is properly cited.

\begin{abstract}
Opportunistic pathogens related to degradation in water quality are of concern to both wildlife and public health. The objective of this study was to identify spatial, temporal, and environmental risk factors for E. coli colonization among Atlantic bottlenose dolphins (Tursiops truncatus) inhabiting the Indian River Lagoon (IRL), FL between 2003 and 2007. Age, gender, capture location, coastal human population density, proximity of sewage treatment plants, number of septic tanks, cumulative precipitation 48 hrs and 30 days prior to capture, salinity, and water temperature were analyzed as potential risk factors. Highest E. coli colonization rates occurred in the northern segments of the IRL. The risk of $E$. coli colonization was the highest among the youngest individuals, in counties with the highest cumulative rainfall $48 \mathrm{hrs}$ and in counties with the highest number of septic systems during the year of capture. The prevalence of colonization was the highest during 2004, a year during which multiple hurricanes hit the coast of Florida. Septic tanks, in combination with weather-related events suggest a possible pathway for introduction of fecal coliforms into estuarine ecosystems. The ability of $E$. coli and related bacteria to act as primary pathogens or cause opportunistic infections adds importance of these findings.
\end{abstract}

\section{Introduction}

The human population inhabiting the coastal areas in Florida increased by $75 \%$ from 1980 to 2003 and continues to expand [1]. This substantial growth creates environmental stress on adjacent marine ecosystems and is of particular concern along the Indian River Lagoon (IRL), which comprises $40 \%$ of Florida's east coast. Changes in the environment as a result of anthropogenic activities can influence the proliferation and distribution of fecal coliform bacteria and potential pathogens including Escherichia coli [2]. There is strong evidence to suggest a link between environmental stressors and infectious pathogens [3-6]. Specifically, increased burdens on sewage systems have the potential to increase the numbers of fecal coliform bacteria that ultimately reach coastal and estuarine waters. Fecal coliform bacteria are an important indicator system to assess the impact of anthropogenic pollution on coastal ecosystems and public health.

Certain strains of $E$. coli are well-recognized threat to human health while others serve as an indicator of fecal pollution, particularly among individuals exposed to coastal waters through recreation or the consumption of contaminated seafood [7]. There are six major strains of E. coli with varying pathogenicity, production of enterotoxins, and plasmid virulence factors [8]. Transmission among humans occurs primarily through ingestion of contaminated food, 
water, or by contact with fomites. Infection with pathogenic strains of $E$. coli causes gastrointestinal disease which can include enteritis, hemorrhagic colitis, hemolytic uremic syndrome, and additional complications in compromised individuals [8]. Upon entering the environment, E. coli will persist, grow, and colonize both humans and wildlife. E. coli has been identified as the causative agent in multiple disease outbreaks associated with swimming and other recreational exposure to water in the United States and Canada [9-12].

Colonization with E. coli is not limited to human populations. The organism has commonly been cultured from a variety of aquatic wildlife including bottlenose dolphins, harbor seals, elephant seals, ducks, geese, and seagulls [1316]. Previous research on E. coli among marine organisms has established that exposure to multiple environmental factors is associated with increased risk of colonization. Among filter-feeding shellfish (oysters, clams, and mussels), a strong seasonal trend in risk of colonization corresponding with increases in average water temperature and rainfall was identified $[17,18]$. Similarly, the frequency of detection of fecal pathogens including E. coli increased during the rainy season among southern sea otters (Enhydra lutris kenyoni) [2].

Previous reports have identified E. coli colonization in bottlenose dolphins (Tursiops truncatus) from multiple geographic areas, including estuarine populations $[15,19$, 20]. Colonization was reported to be as high as $69 \%$ of dolphins sampled in Charleston Harbor, SC and the Indian River Lagoon, FL (IRL) with $25 \%$ of the isolates resistant to one or more antibiotics [16]. However, no previous studies have attempted to determine whether the patterns of $E$. coli colonization among bottlenose dolphins are associated with environmental risk factors.

Therefore, the objective of this study was to identify environmental and other risk factors for E. coli colonization among free-ranging dolphins in the IRL. We incorporated the spatial distribution of members of this estuarine dolphin population with biological and environmental characteristics to explore exposures at an individual level. The large size of the estuary, varied land use bordering the lagoon, and availability of an extensive data base on the health of the bottlenose dolphin population, including microbiological data, makes this population well suited for investigation. To our knowledge, the current study is the first to examine the colonization of $E$. coli among dolphins using a spatial and temporal risk assessment model.

\section{Methods}

2.1. Dolphin HERA Project. Data were collected as a part of the Bottlenose Dolphin Health and Risk Assessment Project (HERA), a collaborative multidisciplinary effort to assess health in two estuarine regions along the eastern coast of the United States [21]. All research was approved by the Harbor Branch Oceanographic Institution Animal Care and Use Committee. Dolphins were sampled from the IRL in June of each year between 2003 and 2007. Age was determined following extraction of a tooth under local anesthesia using previously described methods [22].
2.2. Sample Collection. Fecal samples for microbial isolation were collected using Amies culturette swabs (MML Diagnostics, Troutdale, OR). Fecal material was collected in sterile $15 \mathrm{~mL}$ conical vials opportunistically as the animal defecated and transferred to a sterile swab or by inserting the swab directly into the rectum. Swabs were stored on ice packs in coolers and shipped overnight to a commercial laboratory on cold packs.

2.3. Organism Identification. All microbial analyses were conducted by Micrim Laboratories, Fort Lauderdale, FL. Standard methods were used for organism identification from all fecal cultures, including growth on selective and differential media, colony morphology, gram stain, and biochemical reactions [23]. Additional microbial information generated from the HERA project has been described elsewhere [20]. E. coli was identified using standard methods including a gram stain and growth on Sorbitol-MacConkey agar and blood agar incubated for $24 \mathrm{hrs}$ at $37^{\circ} \mathrm{C}$ [23]. Animals for which fecal samples showed heavy growth with E. coli as the dominant species were classified as colonized.

2.4. Antimicrobial Sensitivity Testing. Antibiotic resistance of E. coli was determined by disk diffusion assays [23]. The protocol included standardized inocula of bacteria swabbed onto the surface of Mueller-Hinton agar plates. Impregnated antimicrobial discs were placed onto the inoculated agar and the samples were incubated for 24 to 48 hours at $37^{\circ} \mathrm{C}$. The tested agents were amikacin, amoxicillin-clavulanic acid, ampicillin, cefotaxime, ceftazidime, cephalothin, chloramphenicol, clindamycin, ciprofloxacin, enrofloxacin, erythromycin, furadantin, gentamicin, marbofloxacin, oxacillin, penicillin, piperacillin, septra/bactrim, and tetracycline. Zones of inhibition were measured, and the Clinical and Laboratory Standards Institute (CLSI) antimicrobial susceptibility testing standards M2-A9 and M7-A7 were applied.

2.5. Environmental Data. The IRL is a shallow-water ecosystem that encompasses 40 percent of Florida's east coast and is an aggregate of three estuaries. Due to limited tidal exchange, the lagoon is vulnerable to the influx of chemical and biological pollutants. Water quality in the IRL has deteriorated during the past five decades because of watershed alterations and changes in land drainage patterns. Decreased water quality is attributed primarily to fresh- and storm-water discharges that alter salinity and water clarity and introduce nutrients and pollutants into the system [24].

The study area was divided into 6 segments based on hydrodynamic and geographic features (Figure 1) [25]. Dolphins were assigned to an IRL segment based on the individual's capture location during HERA. In addition, each dolphin was assigned to a county bordering the IRL based on the GPS coordinates of its capture location. Due to the high degree of site fidelity exhibited by the IRL dolphin population, capture location can be used to represent an approximation of each individual's relative distribution within the lagoon [26].

Human population density for each segment of the IRL was calculated using the 2000 US Census data for census 


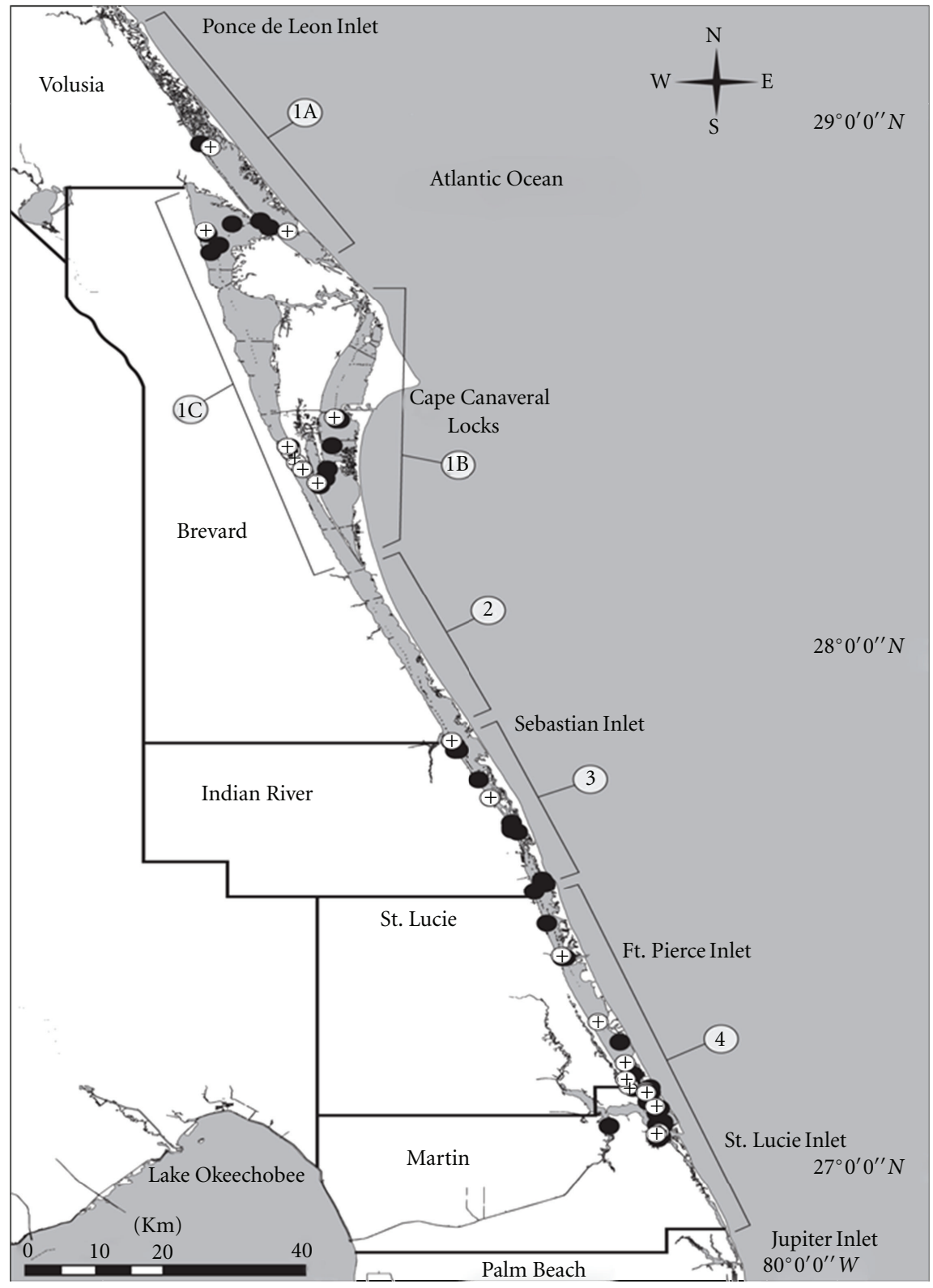

FIGURE 1: Spatial distribution of E. coli positive and negative dolphins with spatial segments by Florida counties in the Indian River Lagoon, FL.

tracts directly bordering the IRL [1]. Density was measured as inhabitants per square mile and categorized into four groups based on the data distribution. The number and location of sewage treatment facilities along the lagoon were calculated for each segment using data from the Florida Department of Environmental Protection online Geographical Information Systems (GIS) mapping resources [27]. Rainfall, water temperature, and salinity data were obtained from the water management districts' online databases [28, 29].

Additional environmental data were analyzed at the county level due to limited availability of local data for these parameters. Locations and totals of new and existing septic systems by year in which individuals were captured were obtained through the Florida Department of Health, Division of Environmental Health from county permit data. Forty-eight hour and 30-day cumulative rainfall were calculated using daily radar rainfall estimates (inches) from monitoring sites near the lagoon by county. Mean water temperature and salinity 30 days prior to capture were also calculated from monitoring stations located in the lagoon by county. Spatial mapping was done using ArcMap 9.3 (ESRI, Redlands, Calif, USA).

2.6. Statistical Analysis. Environmental risk factors included water temperature, salinity, population density, sewage treatment plants, septic systems, and rainfall. Dolphin age and human population density were categorized in quartiles 
based on the data distribution. Water temperature, salinity, population density, sewage treatment plants, septic systems, and rainfall were categorized into tertiles for analysis.

Dolphins with $E$. coli colonization (cases) were compared to those from which E. coli was not cultured (controls). Logistic regression analyses were conducted to generate risk estimates for each quartile of exposure using the lowest quartile in each exposure category as the referent. Risk estimates were expressed as odds ratios (OR) with their $95 \%$ confidence intervals (CI). Univariate analysis was used to determine which variables were independent risk factors for colonization prior to inclusion in a multivariate model. Those independent environmental and demographic risk factors found to be statistically significant in the univariate analysis were included in the multivariate logistic model. A forward stepwise approach with the likelihood ratio test and a $P$ value of $<0.05$ were used as inclusion criteria for covariates in the final model. Adjusted odds ratios and their 95\% CI were generated for each independent variable. Model fit was assessed using the Hosmer and Lemeshow test [30]. Odds ratios with a $95 \% \mathrm{CI}$ that did not include the null value of one were considered statistically significant at $P<0.05$. All analyses were performed using PASW Statistics 17.0 for Windows (SPSS Inc., Chicago Ill, USA).

\section{Results}

A total of 96 individual dolphins, captured and released between 2003 and 2007 in the IRL, received fecal swabs and were included in the analysis. E. coli was isolated from 39 dolphins, (40.6\%) 34 of which had the full suite of data necessary for this analysis. The observed prevalence of E. coli is identical to the $41 \%$ described by Buck et al. [19] using similar microbiology methods in a study of stranded cetaceans from the northeast and southeast US coasts. The animals included in this study are a subset of the complete HERA microbial screening of IRL and Charleston, SC dolphins reported previously [20]. Among the individual animal demographic variables examined for risk of colonization in univariate analysis, age contributed significantly with animals less than 6.5 years of age at the highest risk $(\mathrm{OR}=3.8,95 \% \mathrm{CI} 1.5,9.6)$ compared to individuals 16 years of age or older (Table 1). Gender was not associated with risk of colonization.

The prevalence of $E$. coli colonization differed significantly across the five years of dolphin sampling and was the highest in $2004(62.1 \%)$ and the lowest in 2003 (8.3\%). Animals cultured in 2004 and 2005 were 18.0 (95\% CI $3.52,91.9)$ and $7.7(95 \%$ CI 1.35, 43.9) times more likely, respectively, to be positive for E. coli compared with those captured during 2003 (Table 2).

The prevalence of colonization also differed spatially. Dolphins sampled from the northern segments of the IRL $(1 \mathrm{~A}, 1 \mathrm{~B}, 1 \mathrm{C})$ had a higher prevalence of $E$. coli in their feces $(43.9 \%)$ than those sampled from the two southern segments (3 and 4) (29.6\%), but the difference was not statistically significant. ( $P=0.13$ by Chi-squared analysis). However, a significant difference in the risk of colonization was found with dolphins sampled from the northernmost region of the lagoon (segment 1A) 4.3 (95\% CI 0.97, 19.4) times more likely to have a positive culture compared to the southernmost segment (Segment 4). In contrast, two segments ( 3 and 1B) exhibited a reduced risk $0.29(95 \%$ CI $0.0,1.4)$ and $0.34(95 \%$ CI $0.0,1.7)$ when compared to the northernmost segment (1A) of the lagoon (Table 2, Figure 1).

There was little evidence that environmental factors were associated with the risk of E. coli colonization at the segment level (Table 3). Human population density and the number of sewage treatment plants in the segment did not contribute to the risk of colonization. Similarly, water temperature and salinity at the site of capture were not significant risk factors for colonization. However, several associations between environmental factors and risk of $E$. coli colonization in IRL dolphins were found in countylevel analyses. The number of septic tanks in the county during the year of capture was significantly associated with E. coli colonization. Animals in areas with $\geq 82,244$ tanks (mean 126,438) during the year of capture were 6.6 (95\% CI 2.1, 20.5) times more likely to be colonized compared to those in areas with $\leq 70,286$ septic tanks (mean 56,262). Precipitation of total 30 days prior to capture was not a significant risk factor. In contrast, animals captured when total rainfall $48 \mathrm{hr}$ prior to capture was between 0.24 and 0.80 inches were 10.3 (95\% CI 2.9, 36.9) times more likely to be colonized compared to captures with rainfall $\leq 0.23$ and $\leq 0.81$ inches. However, the risk of colonization was not significantly increased for the highest level of $48 \mathrm{hr}$ precipitation $>0.81$ inches.

In the final multivariate model age, the number of septic tanks and $48 \mathrm{hr}$ precipitation were included as risk factors. Septic tanks were significantly associated with colonization when adjusted for the remaining covariates with a stepwise increase in risk to 6.3 (95\% CI 1.0, 39.7) amongst the highest totals. The highest two categories of total $48 \mathrm{hr}$ precipitation both contributed to an increased risk of colonization (OR 8.4, 95\% CI 2.0, 35.4 and OR 9.0, 95\% CI 1.2, 70.2) (Table 4). Animals 6.5 years or younger were 8.6 times more likely to be colonized (OR 8.6, 95\% CI 1.3, 57.3) compared to older individuals after adjusting for other covariates.

\section{Discussion}

E. coli is a ubiquitous organism and has been isolated from feces obtained from bottlenose dolphins in multiple geographic areas $[16,19,20]$. The overall prevalence of $E$. coli in IRL dolphins between 2003 and 2007 was 52\%, which is similar to the previously reported prevalence of $48 \%$ from the IRL in 2003 [16].

The finding that prevalence of $E$. coli colonization was the highest among the youngest age group of dolphins is consistent with the development of acquired immunity against this bacterium. The immune response to gastrointestinal infection with E. coli is mediated primarily through IgA secreted by the gut-associated lymphoid tissue located within the small intestine [13]. Repeated exposures to the organism during the first years of life appear to contribute to the development of acquired immunity over time as shown in 
TABLE 1: Univariate analysis of individual risk factors for positive and negative $E$. coli colonization among bottlenose dolphins $(n=$ number of individual dolphins).

\begin{tabular}{|c|c|c|c|}
\hline & E. coli $+n(\%)$ & E. coli $-n(\%)$ & OR $(95 \% \mathrm{CI})$ \\
\hline \multicolumn{4}{|l|}{ Age* } \\
\hline$<6.5$ & $11(50.0)$ & $11(50.0)$ & $3.8(1.5,9.6)$ \\
\hline $6.5-10.9$ & $11(39.3)$ & $17(60.7)$ & $1.9(0.7,4.8)$ \\
\hline $11.0-15.9$ & $9(39.1)$ & $14(60.9)$ & $2.5(1.0,6.6)$ \\
\hline$>16.0$ & $3(18.7)$ & $13(81.3)$ & 1.00 \\
\hline \multicolumn{4}{|l|}{ Gender } \\
\hline Female & $10(35.7)$ & $18(64.3)$ & 1.00 \\
\hline Male & $24(35.3)$ & $44(64.7)$ & $1.2(0.6,2.3)$ \\
\hline
\end{tabular}

* Ages available for 55 of 62 E. coli.

TAble 2: Distribution of E. coli positive and negative dolphins in the Indian River Lagoon, FL, by segment and year of capture with odds ratios and 95\% confidence intervals.

\begin{tabular}{|c|c|c|c|}
\hline & E. coli $+n(\%)$ & E. coli $-n(\%)$ & OR $(95 \% \mathrm{CI})$ \\
\hline \multicolumn{4}{|l|}{ Segment } \\
\hline 4 & $14(35.0)$ & $26(65.0)$ & 1.00 \\
\hline 3 & $2(13.3)$ & $13(86.7)$ & $0.3(0.1,1.4)$ \\
\hline $1 \mathrm{C}$ & $9(50.0)$ & $9(50.0)$ & $1.8(0.6,5.7)$ \\
\hline $1 \mathrm{~B}$ & $2(15.4)$ & $11(84.6)$ & $0.3(0.1,1.7)$ \\
\hline $1 \mathrm{~A}$ & $7(70.0)$ & $3(30.0)$ & $4.3(1.0,19.4)$ \\
\hline \multicolumn{4}{|c|}{ Year of capture } \\
\hline 2003 & $2(8.3)$ & $22(91.7)$ & 1.00 \\
\hline 2004 & $18(62.1)$ & $11(37.9)$ & $18.0(3.5,91.9)$ \\
\hline 2005 & $7(41.2)$ & $10(58.8)$ & $7.7(1.3,43.9)$ \\
\hline 2006 & $5(29.4)$ & $12(70.6)$ & $4.6(0.8,27.3)$ \\
\hline 2007 & $2(22.2)$ & $7(77.8)$ & $3.1(0.4,26.6)$ \\
\hline
\end{tabular}

humans in developing countries where childhood infection with enterotoxigenic strains is a major public health problem [31].

The spatial differences in colonization are of interest because the northern portion of the lagoon is less urbanized relative to the southern regions. Water temperature and salinity showed little variability between IRL segments and was not associated with colonization. This is in contrast to a previous report on risk factors for human enteric infections which demonstrated an increase in infections associated with higher ambient temperatures [32].

Increased precipitation associated with increased microbial colonization has been reported for some coastal species including shellfish and southern sea otters (Enhydra lutris nereis) $[2,17,18]$. We found an association between colonization of E. coli and rainfall during the $48 \mathrm{hrs}$ prior to sampling but not with precipitation 30 days prior to sampling suggesting that runoff from terrestrial sources of fecal contamination from wildlife, domestic animals, or humans could contribute to the risk of enteric infection in estuarine dolphins.

Among the anthropogenic factors examined, human population density was not associated with an increase risk of colonization. Similarly, the risk of colonization with antibiotic-resistant $E$. coli in stranded northern elephant seals along the California coastline did not follow a dose-response pattern with human population density [33]. This is in contrast to a previous study that determined an increased risk of human illness associated with increased exposure to coastal waters near densely populated areas compared to less developed coastlines [34].

The number of septic tanks in the county of capture was a strong risk factor for colonization, with odds ratios over 6 for the highest category in both univariate and adjusted analyses. Further, the northern regions of the lagoon where $E$. coli colonization was most prevalent also had a larger number of septic tanks compared to the southern portions. When compared to areas on sewer systems, high concentrations of septic tanks show elevated levels of seepage [35]. Increased septic tank usage has been associated with higher fecal coliform bacteria densities in other coastal environments [36, 37].

Animals sampled during 2004 and 2005 were more likely to be colonized compared to 2003 and 2006-2007. The peak in colonization coincided with multiple hurricanes and water discharge events from inland lakes along the Florida coast in 2004. The resulting rain, discharge, wind, and erosive wave action likely created ideal conditions for washing of feces-contaminated water into the lagoon from low-lying septic systems and possible release of bacteria from 
TABLE 3: Univariate analysis of environmental risk factors for E. coli colonization among bottlenose dolphins.

\begin{tabular}{|c|c|c|c|}
\hline & E. coli $+n(\%)$ & E. coli $-n(\%)$ & OR $(95 \% \mathrm{CI})$ \\
\hline \multicolumn{4}{|c|}{ Segment level analysis } \\
\hline \multicolumn{4}{|c|}{ Sewage treatment facilities } \\
\hline$\leq 8$ & $9(26.5)$ & $14(22.6)$ & 1.00 \\
\hline $9-19$ & $11(32.4)$ & $22(35.5)$ & $0.8(0.3,2.3)$ \\
\hline$\geq 20$ & $14(41.2)$ & $26(41.9)$ & $0.8(0.3,2.4)$ \\
\hline \multicolumn{4}{|l|}{ Population density } \\
\hline$<595.39$ & $9(26.5)$ & $14(22.6)$ & 1.00 \\
\hline $595.39-754.39$ & $9(26.5)$ & $9(14.5)$ & $1.6(0.4,5.4)$ \\
\hline $754.40-771.41$ & $2(5.9)$ & $13(21.0)$ & $0.2(0.0,1.3)$ \\
\hline$\geq 771.42$ & $14(41.2)$ & $26(41.9)$ & $0.8(0.3,2.4)$ \\
\hline \multicolumn{4}{|c|}{ County-level analysis } \\
\hline \multicolumn{4}{|c|}{$48 \mathrm{hr}$ precipitation (inches) ${ }^{*}$} \\
\hline$\leq 0.23$ & $3(13.3)$ & $24(46.4)$ & 1.00 \\
\hline $0.24-0.80$ & $19(63.3)$ & $12(21.4)$ & $10.3(2.9,36.9)$ \\
\hline$\geq 0.81$ & $7(23.3)$ & $18(32.1)$ & $2.5(0.6,9.9)$ \\
\hline \multicolumn{4}{|c|}{30 day precipitation (inches) } \\
\hline$\leq 5.72$ & $16(47.1)$ & $20(32.3)$ & 1.00 \\
\hline $5.73-6.24$ & $4(11.8)$ & $26(41.9)$ & $0.2(0.1,0.7)$ \\
\hline$\geq 6.25$ & $14(41.2)$ & $16(25.8)$ & $1.1(0.4,2.9)$ \\
\hline \multicolumn{4}{|c|}{ Water temperature $\left({ }^{\circ} \mathrm{C}\right)^{*}$} \\
\hline$\geq 30.2$ & $12(48.0)$ & $21(39.6)$ & 1.00 \\
\hline $29.4-30.1$ & $12(48.0)$ & $15(28.3)$ & $1.4(0.5,4.0)$ \\
\hline 28.4-29.39 & $1(4.0)$ & $17(32.1)$ & $0.1(0.0,0.9)$ \\
\hline \multicolumn{4}{|l|}{ Salinity (ppt)* } \\
\hline$\leq 23.01$ & $11(44.0)$ & $20(37.7)$ & 1.00 \\
\hline $23.02-22.84$ & $3(12.0)$ & $26(49.1)$ & $0.2(0.1,0.8)$ \\
\hline$\geq 33.85$ & $11(44.0)$ & $7(13.2)$ & $2.9(0.7,9.5)$ \\
\hline \multicolumn{4}{|c|}{ Septic tanks per year } \\
\hline$\leq 70.286$ & $7(20.6)$ & $27(43.5)$ & 1.00 \\
\hline $70.287-82.243$ & $10(29.4)$ & $25(40.3)$ & $1.5(0.5,4.7)$ \\
\hline$\geq 82.244$ & $17(50.0)$ & $10(16.1)$ & $6.6(2.1,20.5)$ \\
\hline
\end{tabular}

${ }^{*}$ Data not available for all individuals.

TABLe 4: Multivariate logistic regression analysis of risk factors for E. coli colonization among bottlenose dolphins.

\begin{tabular}{|c|c|c|c|}
\hline & Adjusted OR & $95 \% \mathrm{CI}$ & $P$ value \\
\hline \multicolumn{4}{|l|}{ Age } \\
\hline$>16.0$ & 1.0 & - & - \\
\hline $11.0-15.9$ & 3.5 & $0.6,19.6$ & 0.15 \\
\hline $6.5-10.9$ & 5.3 & $0.9,30.1$ & 0.06 \\
\hline$<6.5$ & 8.6 & $1.3,57.3$ & 0.03 \\
\hline \multicolumn{4}{|c|}{$48 \mathrm{hr}$ precipitation (inches) ${ }^{* *}$} \\
\hline$\leq 0.23$ & 1.0 & - & - \\
\hline $0.24-0.80$ & 2.1 & $2.0,35.4$ & $<0.01$ \\
\hline$\geq 0.81$ & 2.2 & $1.2,70.2$ & 0.04 \\
\hline \multicolumn{4}{|c|}{ Septic tanks per year** } \\
\hline$\leq 70.286$ & 1.0 & - & 一 \\
\hline $70.287-82.243$ & 1.9 & $0.2,15.4$ & 0.53 \\
\hline$\geq 82.244$ & 6.3 & $1.0,39.7$ & 0.05 \\
\hline
\end{tabular}


the sediment. Previous studies have identified increases in fecal coliform counts as a result of hurricane events in the United States [38, 39]. An increase in fecal coliforms was also documented in areas without post hurricane flooding [40]. Non point sources, specifically land runoff have been associated with septic seepage [41]. Septic seepage associated with hurricane events may have been responsible for the spatial and temporal increase in E. coli colonization observed in the study population.

The current study is limited by the cross-sectional design which did not permit longitudinal assessment of E. coli colonization to determine whether these were transient or more permanent events. Seasonal changes in bacterial counts and rainfall were not reflected because all dolphin sampling took place during June and July. Finally, this study was unable to distinguish commensal infections with E. coli from those that may have been pathogenic.

The study of fecal coliform bacteria in estuarine bottlenose dolphins is a useful barometer of ecosystem health and anthropogenic impacts on the local environment. Our results suggest that anthropogenic influences exacerbated by meteorological events are significant risks factors associated with $E$. coli colonization among bottlenose dolphins. Bottlenose dolphins are an important sentinel species for humans since these estuarine animals are exposed to many of the same environmental hazards as people who live in coastal areas or use the marine environment recreationally [42]. Therefore, the environmental risk factors identified for E. coli colonization in this dolphin population may represent shared risk that has impact on public health.

\section{Acknowledgment}

This work was conducted under the NMFS permit 998-1678 issued to Dr. G. Bossart as a part of the Dolphin Health and Risk Assessment of Bottlenose Dolphins Project (HERA). Microbial isolations were performed by Dr. John Pisani, Micrim Laboratories, Fort Lauderdale, FL. Special thanks to Steve McCulloch, Juli Goldstein, and the numerous collaborators and volunteers who participated in the Dolphin HERA project. The authors also thank Wayne McFee for dolphin age analyses and Julie Zimmerman from the Florida Department of Environmental Protection for assistance in obtaining water quality data and Elizabeth Murdoch for her graphical support. Additional thanks to Laura Webster and Dr. Peter McCarthy for reviewing the paper.

\section{References}

[1] U.S. Census Bureau, Untied States Census, 2000, http://www .census.gov/.

[2] M. A. Miller, B. A. Byrne, S. S. Jang et al., "Enteric bacterial pathogen detection in southern sea otters (Enhydra lutris nereis) is associated with coastal urbanization and freshwater runoff," Veterinary Research, vol. 41, no. 1, 2010.

[3] P. R. Epstein, "Emerging diseases and ecosystem instability: new threats to public health," American Journal of Public Health, vol. 85, no. 2, pp. 168-172, 1995.
[4] P. Daszak, A. A. Cunningham, and A. D. Hyatt, "Anthropogenic environmental change and the emergence of infectious diseases in wildlife," Acta Tropica, vol. 78, no. 2, pp. 103116, 2001.

[5] M. H. Woodford, "Veterinary aspects of ecological monitoring: the natural history of emerging infectious diseases of humans, domestic animals and wildlife," Tropical Animal Health and Production, vol. 41, no. 7, pp. 1023-1033, 2009.

[6] J. C. Rhyan and T. R. Spraker, "Emergence of diseases from wildlife reservoirs," Veterinary Pathology, vol. 47, no. 1, pp. 3439, 2010.

[7] R. Fayer, J. P. Dubey, and D. S. Lindsay, "Zoonotic protozoa: from land to sea," Trends in Parasitology, vol. 20, no. 11, pp. 531-536, 2004.

[8] P. Braam, "Diarrhea caused by Escherichia coli", in Control of Communicable Diseases Manual, D. L. Heymann, Ed., pp. 160171, American Public Health Association, 18th edition, 2004.

[9] W. E. Keene, J. M. McAnulty, F. C. Hoesly et al., "A swimming-associated outbreak of hemorrhagic colitis caused by Escherichia coli O157:H7 and Shigella sonnei," New England Journal of Medicine, vol. 331, no. 9, pp. 579-584, 1994.

[10] C. C. Mudgett, R. Ruden, and C. C. Austin, "A beachassociated outbreak of Escherichia coli O157:H7," Journal of Environmental Health, vol. 60, no. 9, pp. 7-13, 1998.

[11] M. S. Friedman, T. Roels, J. E. Koehler, L. Feldman, W. F. Bibb, and P. Blake, "Escherichia coli O157:H7 outbreak associated with an improperly chlorinated swimming pool," Clinical Infectious Diseases, vol. 29, no. 2, pp. 298-303, 1999.

[12] M. G. Bruce, M. B. Curtis, M. M. Payne et al., "Lakeassociated outbreak of Escherichia coli O157:H7 in Clark County, Washington, August 1999," Archives of Pediatrics and Adolescent Medicine, vol. 157, no. 10, pp. 1016-1021, 2003.

[13] H. Steinsland, P. Valentiner-Branth, H. K. Gjessing, P. Aaby, K. A. Mølbak, and H. Sommerfelt, "Protection from natural infections with enterotoxigenic Escherichia coli: longitudinal study," The Lancet, vol. 362, no. 9380, pp. 286-291, 2003.

[14] C. M. Steele, R. N. Brown, and R. G. Botzler, "Prevalences of zoonotic bacteria among seabirds in rehabilitation centers along the Pacific Coast of California and Washington, USA," Journal of Wildlife Diseases, vol. 41, no. 4, pp. 735-744, 2005.

[15] S. K. Lockwood, J. L. Chovan, and J. K. Gaydos, "Aerobic bacterial isolations from harbor seals (Phoca vitulina) stranded in Washington: 1992-2003," Journal of Zoo and Wildlife Medicine, vol. 37, no. 3, pp. 281-291, 2006.

[16] T. W. Greig, J. A. Bemiss, B. R. Lyon, G. D. Bossart, and P. A. Fair, "Prevalence and diversity of antibiotic resistant Escherichia coli in bottlenose dolphins (Tursiops truncatus) from the Indian River Lagoon, Florida, and Charleston Harbor area, South Carolina," Aquatic Mammals, vol. 33, pp. 185-194, 2007.

[17] R. J. Lee and O. C. Morgan, "Environmental factors influencing the microbiological contamination of commercially harvested shellfish," Water Science and Technology, vol. 47, no. 3, pp. 65-70, 2003.

[18] C. Chávez, V. P. Sedas, E. O. Borunda, and F. L. Reynoso, "Influence of water temperature and salinity on seasonal occurrences of Vibrio cholerae and enteric bacteria in oysterproducing areas of Veracruz, México," Marine Pollution Bulletin, vol. 50, no. 12, pp. 1641-1648, 2005.

[19] J. D. Buck, N. A. Overstrom, G. W. Patton, H. F. Anderson, and J. F. Gorzelany, "Bacteria associated with stranded cetaceans from the northeast USA and southwest Florida Gulf coasts," Diseases of Aquatic Organisms, vol. 10, no. 2, pp. 147-152, 1991. 
[20] A. M. Schaefer, J. D. Goldstein, J. S. Reif, P. A. Fair, and G. D. Bossart, "Antibiotic-resistant organisms cultured from atlantic bottlenose dolphins (tursiops truncatus) inhabiting estuarine waters of charleston, sc and Indian River Lagoon, FL," EcoHealth, vol. 6, no. 1, pp. 33-41, 2009.

[21] P. A. Fair and G. D. Bossart, "Overview of the bottlenose dolphin health and risk assessment project. Synopsis of Researcher Meeting Bottlenose Dolphin Health and Risk Assessment Project," NOAA Technical Memorandum NOS NCCOS, vol. 10, pp. 22-24, 2005.

[22] A. Hohn, M. Scott, R. Wells et al., "Growth layers in teeth from free-ranging, known age bottlenose dolphins," Marine Mammal Science, vol. 5, pp. 315-342, 1989.

[23] National Committee for Clinical Laboratory Standards, Wayne (PA): The Committee, 1997.

[24] G. I. Scott, M. H. Fulton, E. F. Wirth et al., "Toxicological studies in tropical ecosystems: an ecotoxicological risk assessment of pesticide runoff in South Florida estuarine ecosystems," Journal of Agricultural and Food Chemistry, vol. 50, no. 15, pp. 4400-4408, 2002.

[25] Woodward-Clyde Consultants, "Biological resources of Indian River Lagoon. Indian River Lagoon National Estuary Program,” Tech. Rep. 92f274C, Melbourne, Fla, USA, 1994.

[26] M. Mazzoil, S. D. McCulloch, and R. H. Defran, "Observations on the site fidelity of bottlenose dolphins (Tursiops truncatus) in the Indian River Lagoon, Florida," Florida Scientist, vol. 68, pp. 217-227, 2005.

[27] Florida Department of Health, Division of Environmental Health, Septic tank installation Permits, 2009, http://www.doh .state.fl.us/environment/ostds/statistics/newInstallations.pdf.

[28] South Florida Water Management District, Radar rainfall, 2009, http://my.sfwmd.gov/portal/page/portal/pg_grp_weather/pg_weather_version3.

[29] St. Johns Water Management District, Radar rainfall estimates, 2009, http://webapub.sjrwmd.com/agws/sjrwmdrain/ Rainfall.aspx.

[30] D. W. Hosmer and S. Lemeshow, Applied Logistic Regression, John Wiley \& Sons, New York, NY, USA, 2nd edition, 2000.

[31] F. Qadri, A. M. Svennerholm, A. S. G. Faruque, and R. B. Sack, "Enterotoxigenic Escherichia coli in developing countries: epidemiology, microbiology, clinical features, treatment, and prevention," Clinical Microbiology Reviews, vol. 18, no. 3, pp. 465-483, 2005.

[32] M. Fleury, D. F. Charron, J. D. Holt, O. B. Allen, and A. R. Maarouf, "A time series analysis of the relationship of ambient temperature and common bacterial enteric infections in two Canadian provinces," International Journal of Biometeorology, vol. 50, no. 6, pp. 385-391, 2006.

[33] R. A. Stoddard, E. R. Atwill, F. M. D. Gulland et al., "Risk factors for infection with pathogenic and antimicrobial-resistant fecal bacteria in northern elephant seals in California," Public Health Reports, vol. 123, no. 3, pp. 360-370, 2008.

[34] R. W. Haile, J. S. Witte, M. Gold et al., "The health effects of swimming in ocean water contaminated by storm drain runoff," Epidemiology, vol. 10, no. 4, pp. 355-363, 1999.

[35] L. Y. Steffy and S. S. Kilham, "Elevated $\delta 15 \mathrm{~N}$ in stream biota in areas with septic tank systems in an urban watershed," Ecological Applications, vol. 14, no. 3, pp. 637-641, 2004.

[36] R. B. Reneau and D. E. Pettry, "Movement of coliform bacteria from septic tank effluent through selected coastal plain soils of Virginia," Journal of Environmental Quality, vol. 4, no. 1, pp. 41-44, 1975.

[37] H. Kelsey, D. E. Porter, G. Scott, M. Neet, and D. White, "Using geographic information systems and regression analysis to evaluate relationships between land use and fecal coliform bacterial pollution," Journal of Experimental Marine Biology and Ecology, vol. 298, no. 2, pp. 197-209, 2004.

[38] M. A. Mallin, M. H. Posey, M. R. McIver, D. C. Parsons, S. H. Ensign, and T. D. Alphin, "Impacts and recovery from multiple hurricanes in a Piedmont-Coastal Plain River system," BioScience, vol. 52, no. 11, pp. 999-1010, 2002.

[39] J. H. Pardue, W. M. Moe, D. McInnis et al., "Chemical and microbiological parameters in New Orleans floodwater following hurricane Katrina," Environmental Science and Technology, vol. 39, no. 22, pp. 8591-8599, 2005.

[40] C. D. Sinigalliano, M. L. Gidley, T. Shibata et al., "Impacts of Hurricanes Katrina and Rita on the microbial landscape of the New Orleans area," Proceedings of the National Academy of Sciences of the United States of America, vol. 104, no. 21, pp. 9029-9034, 2007.

[41] E. E. Geldreich, Sanitary Significance of Fecal Coliforms in the Environment, Water Pollution Control Research Series, publication WP-20-3, Federal Water Pollution Control Administration, U.S. Department of the Interior, Cincinnati, Ohio, USA, 1966.

[42] G. D. Bossart, "Marine Mammals as sentinel species for oceans and human health," Oceanography, vol. 19, pp. 44-47, 2006. 


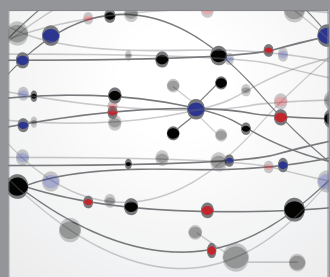

The Scientific World Journal
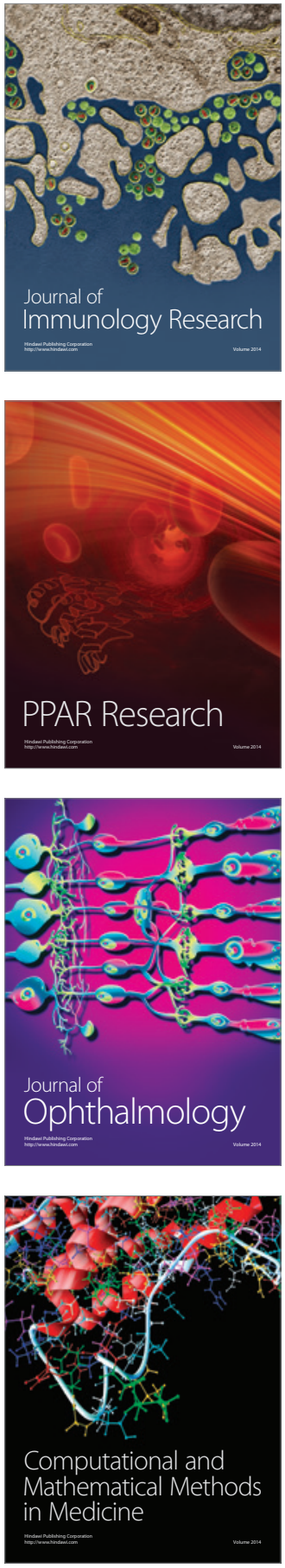

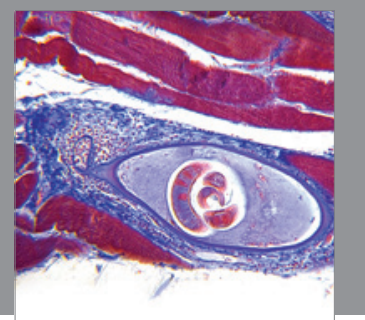

Gastroenterology

Research and Practice
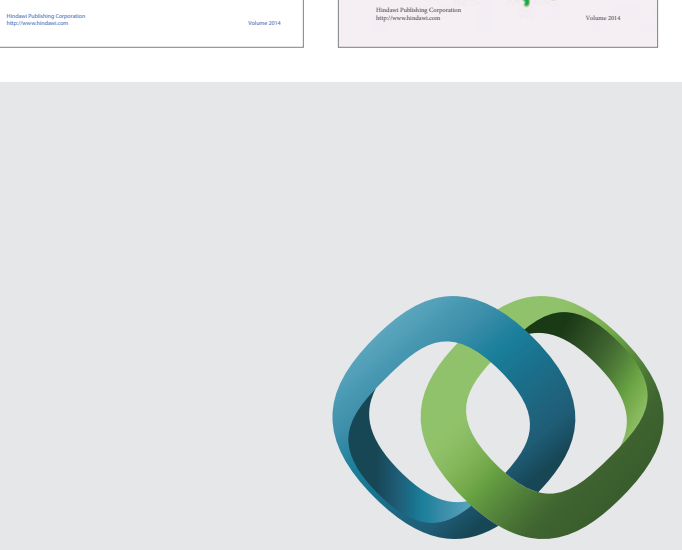

\section{Hindawi}

Submit your manuscripts at

http://www.hindawi.com
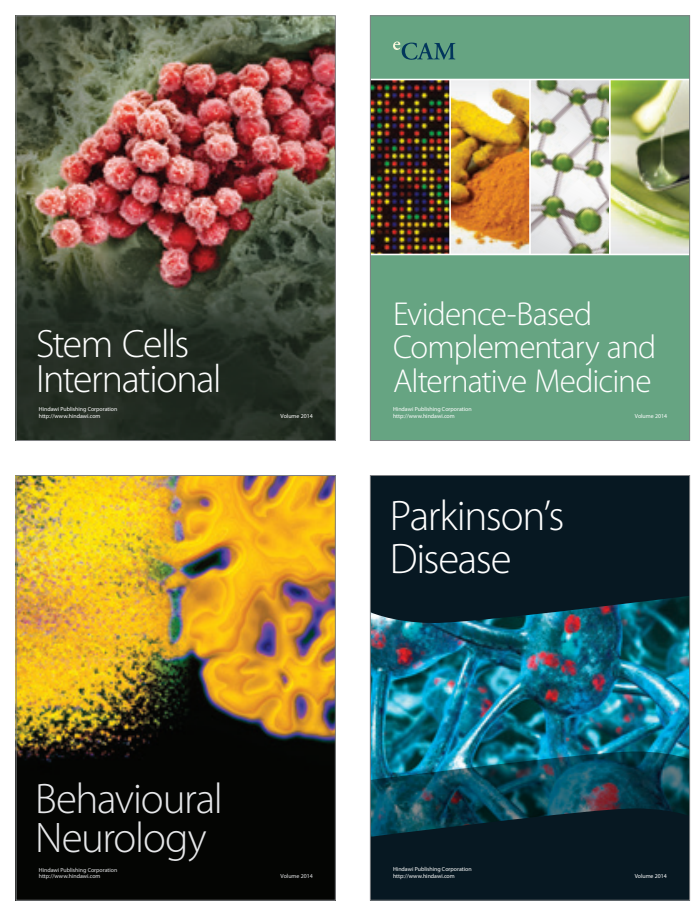

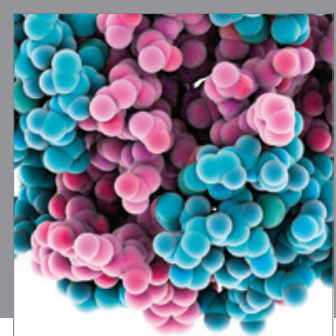

Journal of
Diabetes Research

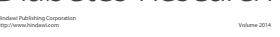

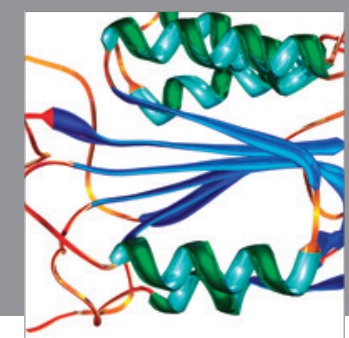

Disease Markers
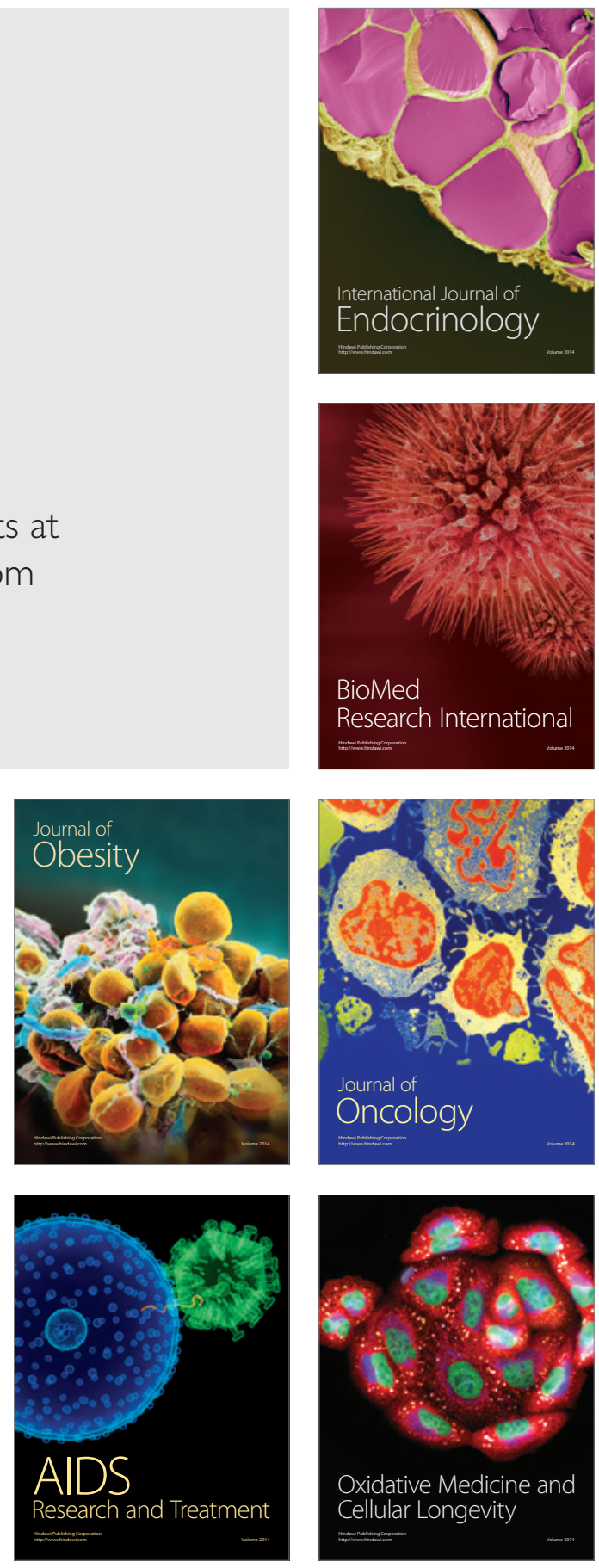